\title{
Introducción a los arácnidos de Huila: Orden Schizomida
}

Perdomo A., Valenzuela J. \& García L. F. (2020). Introducción a los arácnidos de Huila: Orden Schizomida. Bogotá: Surcolombiana

Comentario a cargo de: Dra. Carmen Viera.

Profesora Entomología, Facultad de Ciencias, Universidad de la República. Jefa de Ecología del Comportamiento, IIBCE. MEC.

cviera@fcien.edu.uy

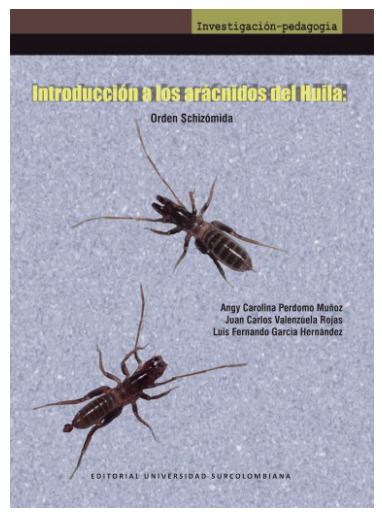

Este libro es un aporte científico y didáctico de dos maestros, Angy Perdomo y Juan Valenzuela que junto al investigador Dr. Luis Fernando García, divulgan la diversidad biológica de los arácnidos, fundamentalmente de los Esquizómidos y brindan herramientas sobre su enseñanza en la educación primaria. Huilla es una localidad colombiana de donde son oriundos los dos primeros autores y utilizan el saber de la fauna local como modelo no sólo del grupo en el que se focalizan, sino que aprovechan el vínculo de cercanía de los alumnos de la zona, como motivación principal.

El libro tiene tres capítulos:

1. los arácnidos dentro de los artrópodos

2. el estudio de la diversidad de arácnidos del Huila

3. implicaciones didácticas del uso de los arácnidos como modelo de enseñanza.

Más allá de la diversidad de una zona específica, el libro muestra la posibilidad de enseñar sobre un grupo animal determinado a escolares, por ello me centraré en recomendar el tercer capítulo donde se enfatiza el papel de los artrópodos en la diversidad animal, como modelo para enseñar sobre temáticas vinculadas a la educación ambiental y conservación. Por ello, indican la importancia de las salidas de campo y como utilizar manualidades y actividades lúdicas, para reconocer diferentes animales en el campo y en el aula.

Además, incluye dibujos realizados por los niños que le dan un toque de frescura y protagonismo a los estudiantes. Muchas veces hemos observado la falta de evaluación de las experiencias didácticas, pero en esta publicación, los autores le dedican una parte importante del capítulo a esta necesaria tarea. La claridad, diagramación e ilustración del libro resultan en una fluida y amena lectura. Solamente la profusa variedad de sugerencias experimentales, sería una causa para su obligada lectura, pero el libro es mucho más que eso, por lo tanto, recomiendo enfáticamente su lectura, no solamente a Maestros, sino también a profesores de Biología de Educación Media. 